\title{
Interleukin 6 receptor as a target for the treatment of rheumatoid arthritis
}

\section{E Choy}

C hronic synovial inflammation and joint damage are cardinal features of rheumatoid arthritis (RA). Although the precise cause remains unknown, cytokines have a major pathogenic role. The therapeutic benefit of antagonists of tumour necrosis factor alpha (TNF $\alpha$ ) and interleukin (IL) l in RA provide the best evidence for the importance of cytokines in mediating synovitis. Although ILl and TNF $\alpha$ blocking treatments are effective, some patients have refractory disease and fail to respond. The reasons for this are yet to be elucidated. In other patients, treatment has had to be withdrawn because of side effects. When anticytokine treatments are withdrawn, in most cases, it is necessary to substitute other disease modifying antirheumatic drugs (DMARDs) because of resurgence in disease activity. Many patients fail to respond to multiple DMARDs, and alternative treatments are needed. As targeting monokines has produced effective treatment of RA, other cytokines have become attractive therapeutic targets. One of these is IL6.

\section{IL6}

IL6 is a $26 \mathrm{kDa}$ pleiotropic cytokine. It was known initially as B cell stimulatory factor 2 because it stimulates B cell growth and maturation. Likewise it is also known as hepatocyte stimulating factor because it activates hepatocytes to produce acute phase reactants such as $\mathrm{C}$ reactive protein and amyloid A. IL6 is produced by a wide range of cell types including lymphocytes, monocytes, fibroblasts, ${ }^{1}$ synoviocytes, ${ }^{2}$ and endothelial cells. ${ }^{3}$ Structurally, it shares homology with other cytokines: oncostatin M, ILl1, leukaemia inhibitory factor, ciliary neurotrophic factor, and cardiotrophin 1. Together, these cytokines constitute the IL6 superfamily. In addition to structural homology, these cytokines use a common signal transduction pathway to stimulate cellular activation. All of the cytokines in the IL6 superfamily bind to either soluble or cell surface cytokine receptor. The cytokine-cytokine receptor complex then binds to a cell surface molecule, gp130. Cellular activation results from activation of gp130. Therefore inhibiting the cytokine, the cytokine receptor, or gpl30 antagonises the effect of the cytokine. Whereas blocking the cytokine or cytokine receptor largely inhibits the biological effect of one cytokine, inhibition of gp130 blocks the function of all the cytokines in the IL6 superfamily.

The function of IL6 has been studied extensively in vitro. It has effects on the adaptive and innate responses as well as on mesenchymal cells. In the adaptive immune response, IL6, alias B cell stimulatory factor, stimulates B cells to differentiate into plasma cells to produce immunoglobulin. It also stimulates the proliferation and differentiation of $\mathrm{T}$ lymphocytes into cytotoxic T cells. IL6 also stimulates the innate immune response through induction of the acute phase response by stimulating hepatocytes and activation of the hypothalamic-pituitary-adrenal axis $^{4}$ and the generation of fever. ${ }^{5}$ In mesenchymal cells, IL6 stimulates haematopoiesis, including stimulation of megakaryocytic progenitors to produce platelets. It also stimulates the formation of osteoclasts and has a major role in the pathogenesis of osteoporosis. Interestingly, in vitro, IL6 can also abrogate inflammation by suppressing ILl and TNF $\alpha$ production and by inducing the release of ILl receptor antagonist and soluble TNF $\alpha$ receptor. ${ }^{6}$ Hence it has been argued that IL6 may regulate rather than mediate inflammation in RA.

\section{IL6 IN RA}

IL6 is one of the most abundant cytokines found in both the joint and blood of patients with active RA. In the synovial joints, it is produced by lymphocytes, monocytes, fibroblasts, ${ }^{1}$ synoviocytes, ${ }^{2}$ and endothelial cells. ${ }^{3}$ Higher levels of IL6 and IL6 receptor (IL6R) have been found in the serum of patients with RA than controls, and in synovial fluid than serum, reflecting local production by the rheumatoid synovium. ${ }^{378}$ Serum IL6 concentration correlates with disease activity ${ }^{9}$ and radiological joint damage. ${ }^{10}$ Levels of IL6 decrease after effective treatment with DMARDs. ${ }^{11}$ Synovial fluid with high levels of IL6 promotes osteoclast activation, and the degree of activation correlates with joint damage in these patients. ${ }^{10}$ However, the precise pathogenic role of IL6 in RA is controversial because it has both proinflammatory and antiinflammatory properties in vitro.

\section{BLOCKING IL6 IN AN ANIMAL MODEL OF RA}

One of the most convincing pieces of evidence that IL6 is essential in the development of RA came from studies in IL6 deficient mice. ${ }^{12}$ Disease susceptible animals (wild-type) were compared with IL6 knockout mice for their susceptibility to induction of arthritis by methylated bovine serum albumin. Characteristically, wild-type animals developed joint inflammation and swelling about nine days after intra-articular injection. However, IL6 knockout mice were resistant to antigen induced arthritis in that no inflammatory response or synovial inflammation was induced. Interestingly, arthritis could be induced in knockout animals if subcutaneous injections of IL6 were given.

In DBA/1J mice, immunisation with bovine type II collagen leads to an inflammatory arthritis resembling RA clinically and histologically. Monoclonal antibody to IL6R reduced the disease severity if given early in the disease process. ${ }^{13}$ Takagi et al treated animals with collagen induced arthritis with a single dose $(0.5-8 \mathrm{mg})$ of the rat anti-(mouse IL6R) monoclonal antibody, MR16-1. Treatment was started 0, 3, 7, or 14 days after immunisation. MR16-1 abrogated arthritis if treatment was given on day 0 or 3 but not 7 or 14 days after disease onset.

Similar blocking of IL6 can improve disease in a primate model of RA. Immunisation with bovine type II collagen induces inflammatory arthritis in cynomolgus monkeys. Blocking IL6 with a humanised anti-(IL6R) monoclonal antibody (rhPM-1; $10 \mathrm{mg} / \mathrm{kg}$ given weekly for 13 weeks) led to disease improvement. ${ }^{14}$ The treatment protocol was similar to the study on DBA/1J mice. ${ }^{13}$

Abbreviations: RA, rheumatoid arthritis; $\mathrm{TNF} \alpha$, tumour necrosis factor alpha; IL, interleukin; DMARD, disease modifying antirheumatic drug; IL6R, LL6 receptor 


\section{BLOCKING IL6 IN PATIENTS WITH RA}

The results from animal models suggested that inhibition of IL6 in patients with RA may be of clinical benefit. In an open label study, Wendling et al ${ }^{15}$ treated five patients with a murine anti-IL6 monoclonal antibody (B-E8, IgGl) given intravenously ( $10 \mathrm{mg} /$ day) daily for 10 consecutive days. ${ }^{15}$ No side effects were noted. Clinical improvement appeared rapidly during the treatment period, with improvement in pain, morning stiffness, the number of tender and swollen joints, and reduction in $\mathrm{C}$ reactive protein. However, murine monoclonal antibodies are antigenic; the use of other murine antibodies produced an antiglobulin response which reduced efficacy and increased anaphylaxis after repeated treatment. ${ }^{16}$ Hence it is unlikely that murine antibodies can be used as routine clinical treatment for RA.

An alternative strategy for blocking IL6 is to target the IL6R. As discussed previously, inhibiting IL6R inhibits the formation of the IL6-IL6R complex which binds to gp130 leading to cellular activation. A recombinant humanised anti-(human IL6R) monoclonal antibody of the IgGl subtype (MRA; Chugai Pharmaceutical Co Ltd) was tested in a phase I/II double blind, randomised, placebo controlled, single dose trial in patients with RA. ${ }^{17}$ The primary objective of the study was to investigate the safety, tolerability, pharmacokinetics, and efficacy of MRA. Patients with active RA who had failed to respond to at least one DMARD were recruited. Concomitant glucocorticoid treatment was allowed if the dose was $\leqslant 7.5 \mathrm{mg}$ prednisolone a day. Forty five patients were randomised to four cohorts: $0.1,1,5$, or $10 \mathrm{mg} / \mathrm{kg}$ MRA. Within each cohort, patients were randomised to receive a single intravenous dose of either placebo or MRA. The primary efficacy end point was the percentage of patients with ACR20 response at week 2 after treatment. Disease and pharmacokinetics were assessed at baseline and weeks 2, 3, 4, 6, and 8 .

The ACR $20 \%$ response criterion was met by $50 \%$ of patients in the $5 \mathrm{mg} / \mathrm{kg}$ group at week 2 and none in the placebo group. Improvement was maintained until week 8. A significant difference in ACR20\% was also noted between the group receiving $10 \mathrm{mg} / \mathrm{kg}$ MRA and that receiving placebo at weeks 6 and 8 . The efficacy in the 5 and $10 \mathrm{mg} / \mathrm{kg}$ groups was further supported by the return of the erythrocyte sedimentation rate and $\mathrm{C}$ reactive protein concentration to normal values. The half life of MRA was dose dependent. In the high dose groups, the plasma half life was about one week. Treatment was well tolerated. Diarrhoea was the most common adverse event, occurring in $17.8 \%$ of patients. No patient developed an antiglobulin response to MRA after a single dose.

\section{CONCLUSION}

IL6 is an important factor in synovial inflammation. Interrupting IL6 signal transduction with the monoclonal antibody to IL6R, MRA, reduces synovial inflammation. MRA appears to be well tolerated and holds promise as a potential new treatment for RA.

\section{Author's affiliation}

E Choy, Academic Department of Rheumatology, GKT School of Medicine, King's College Hospital, London, UK

Correspondence to: DrE Choy, Academic Department of Rheumatology, 2nd Floor, Weston Education Centre, King's College London, Cutcombe Road, London SE5 9PJ, UK; ernest.choy@kcl.ac.uk

\section{REFERENCES}

1 Kishimoto T. Interleukin-6 and its receptor in autoimmunity. J Autoimmun 1992;5(suppl A): 123-32.

2 Guerne PA, Zuraw BL, Vaughan JH, Carson DA, Lotz M. Synovium as a source of interleukin 6 in vitro. Contribution to local and systemic manifestations of arthritis. J Clin Invest 1989:83:585-92

3 Hirano T, Matsuda T, Turner M, Miyasaka N, Buchan G, Tang B, et al. Excessive production of interleukin-6/B cell stimulatory factor-2 in rheumatoid arthritis. Eur J Immunol 1988;18:1797-801.

4 Navarra P, Tsagarakis S, Faria MS, Rees LH, Besser GM, Grossman AB Interleukin-1 and -6 stimulate the release of corticotrophin realising hormone-41 from rat hypothalamus in vitro via the eicosanoid cyclooxygenase pathway. Endocrinology 1990;128:37-44.

5 Kluger MJ, Kozak W, Leon LR, Conn CA. The use of knockout mice to understand the role of cytokines in fever. Clin Exp Pharmacol Physiol 1998;25:141-4.

6 Taga T, Kishimoto T. Gp130 and the interleukin-6 family of cytokines. Annu Rev Immunol 1997; 15:797-819.

7 Houssiau F, Devogelaer JP, Van Damme J, Nagant de Deuxchaisnes C, Van Snick J. Interleukin 6 in synovial fluid and serum of patients with rheumatoid arthritis and other inflammatory arthritides. Arthritis Rheum 1988;31:784-8.

8 Swaak AJ, van Rooyen A, Nieuwenhuis E, Aarden LA. Interleukin-6 (IL-6) in synovial fluid and serum of patients with rheumatic diseases. Scand J Rheumatol 1988; 17:469-74.

9 Dasgupta B, Corkill M, Kirkham B, Gibson T, Panayi G. Serial estimation of interleukin 6 as a measure of systemic disease in rheumatoid arthritis [see comments]. J Rheumatol 1992;19:22-5.

10 Kotake S, Sato K, Kim KJ, Takahashi N, Udagawa N, Nakamura I, et al. Interleukin-6 and soluble interleukin-6 receptors in the synovial fluids from rheumatoid arthritis patients are responsible for osteoclast-like cell formation. J Bone Miner Res 1996; 1 1:88-95.

11 Kotake S, Sato K, Kim KJ, Takahashi N, Udagawa N, Nakamura I, et al. Interleukin-6 and soluble interleukin-6 receptors in the synovial fluids from rheumatoid arthritis patients are responsible for osteoclast-like cell formation. J Bone Miner Res 1996; 1 1:88-95.

12 Boe A, Baiocchi M, Carbonatto M, Papoian R, Serlupi-Crescenzi O. Interleukin 6 knock-out mice are resistant to antigen-induced experimental arthritis. Eur Cytokine Netw 1999; 1 1:1057-64.

13 Takagi N, Mihara M, Moriya Y, Nishimoto N, Yoshizaki K, Kishimoto T, et al. Blockage of interleukin-6 receptor ameliorates joint disease in murine collagen-induced arthritis. Arthritis Rheum 1998:41:2117-21.

14 Mihara M, Kotoh M, Nishimoto N, Oda Y, Kumagai E, Takagi N, et al. Humanized antibody to human interleukin- 6 receptor inhibits the development of collagen arthritis in cynomolgus monkeys. Clin Immunol 2001;98:319-26.

15 Wendling $\mathbf{D}$, Racadot $E$, Wijdenes J. Treatment of severe rheumatoid arthritis by anti-interleukin 6 monoclonal antibody. J Rheumatol 1993;20:259-62

16 Kavanaugh AF, Schulze-Koops H, Davis LS, Lipsky PE. Repeat treatmen of rheumatoid arthritis patients with a murine anti-intercellular adhesion molecule-1 monoclonal antibody. Arthritis Rheum 1997:40:849-53.

17 Choy EH, Isenberg DA, Garrood T, Farrow S, loannou Y, Bird H, et al. Therapeutic benefit of blocking interleukin- 6 activity with an anti-interleukin-6 receptor monoclonal antibody in rheumatoid arthritis: a randomized, double-blind, placebo-controlled, dose-escalation trial. Arthritis Rheum 2002;46:3143-50. 